\title{
Effect of changes in the diet composition on the bacon pig performance
}

\author{
F. GATEL, F. GROSJEAN \\ I.T.C.F., 8, avenue du Président-Wilson, 75116 Paris
}

\begin{abstract}
Two trials were conducted to evaluate the effect of changes in the formulation of diets for growing-finishing pigs. Two types of feeding treatments were compared : an experimental one where animals received two different diets at 3-week intervals and without transition and a control one where animals received during the whole fattening period the same diet with a composition half between the other two diets. In the first trial we studied the effect of a change in the cereal used, in the second that of a change in the protein supplementation by the introduction of spring peas. All diets were formulated so as to supply the same lysine/digestible energy ratio $(2.7 \mathrm{~g} / 1000 \mathrm{kcal})$. In both trials, animals were fed ad libitum with an automatic feeder. Each trial concerned 210 animals, i. e., 105 per treatment. The repeated change in the nature of the cereal or the variation in the level of incorporation of peas did not modify significantly the performance. These results confirm those reported in the literature about the capacity of rapid adaptation of pigs to rather different diets and the absence of effect on the performance (feed intake, growth, slaughter yield) of a change in the raw material.
\end{abstract}

\section{Comparison of three feeding treatments in bacon pigs. Influence of restriction}

\author{
J. CASTAING *, F. GROSJEAN **, F. WILLEQUET ***, P. QUEMERE ***** \\ * A.G.P.M., 122, boulevard Tourasse, 64000 Pau \\ **I.T.C.F., 8, avenue du Président-Wilson, 75116 Paris \\ *** E.D.E. de l'Oise, 3, rue du Musée, 60000 Beauvais \\ **** S.E.R.E.P., Institut Supérieur Agricole, route de Crèvecœur, 60000 Beauvais
}

Two trials were made to compare a progressively restricted feeding from $25 \mathrm{~kg}$ to $103 \mathrm{~kg}$ at slaughter to ad libitum feeding during the growing period followed by a maximum restriction during the finishing period and to ad libitum feeding during the whole fattening period. The dietary energy concentration was $3.300 \mathrm{kcal} / \mathrm{kg}$ and $3.250 \mathrm{kcal} / \mathrm{kg}$, respectively in the first and second trial. These trials involved 192 Large White pigs and 160 crossbred respectively, with the same number of castrated males and females inside the pens.

Over the whole fattening period, daily mean energy intake was $7.60 ; 8.10$; and 8.90 Mcal DE/day in the first trial and $7.41 ; 7.80$ and $8.10 \mathrm{Mcal} \mathrm{DE} /$ day in the second trial. Growth rates $(802,851$ and $902 \mathrm{~g} / \mathrm{d}$ in the first trial and 755,798 and $813 \mathrm{~g} / \mathrm{d}$ in the second one) increased with the energy intake. Feed conversion ratios $(2.87,2.90$ and 3.00 , respectively in the first trial and 3.02, 3.01 and 3.06 in the second one) were slightly higher with ad libitum feeding. Fat deposition increased with energy intake : the muscle percentage (estimated) was $49.2,48.4$ and 46.8 p. 100 , respectively in the first trial and $51.8,50.6$ and $49.1 \mathrm{p} .100$ in the second one. Accordingly, the type of feeding treatment applied to growing-finishing pigs has to be chosen taking into account economic parameters. 